\title{
Comportamento ingestivo de ovinos em gramíneas tropicais
}

Madruga Moreira, S.; Tavares Costa, P.; Albandes Fernandes, T.; Duarte Farias, G.; Oteiro Faria, P.; Farias Silveira, R.; Peter Gonçalves, B.; Denardin Costa, O.; Barbosa Silveira, I. e Pedroso, C.E.

Universidade Federal de Pelotas. Brasil.

\section{PaLAVRAS ChaVE ADICIONAIS}

Comportamento animal.

Ovinocultura.

Pastejo.

Brasil.

\section{RESUMO}

O objetivo desta revisão foi discutir os principais fatores que afetam o comportamento ingestivo de ovinos manejados em pastagens de gramíneas tropicais. Conhecer os hábitos destes animais é importante para se realizar o manejo adequado às suas necessidades, respeitando seu bem-estar e aumentando os índices produtivos. Ovinos pastejam basicamente no período diurno, consumindo cerca de $2-5 \%$ de seu peso corporal por dia, com tempo variando de acordo com a disponibilidade e o tipo de alimento, dificilmente ultrapassando 12 horas, pois tempos maiores interferem em outras atividades. A ruminação, atividade que demanda mais tempo depois do pastejo, divide-se em 15-20 vezes ao longo do dia, variando de poucos minutos a mais de uma hora, sendo maior à noite. A espécie forrageira, devido às suas características físico-químicas e de manejo, influencia a resposta animal. Com baixa disponibilidade de massa de forragem, os ovinos realizam até 65 bocados/minuto, mas em oferta satisfatória, essa frequência pode cair 50\%. A área de bocado é afetada pela estrutura da pastagem. Com maior proporção de folhas há aumento na taxa e peso de bocados. Uma baixa proporção de folhas reduz o peso de bocados, aumenta o intervalo entre estes e o tempo total de pastejo. Os dados sobre o comportamento ingestivo de ovinos em gramíneas tropicais ainda são deficientes, havendo grande divergência entre autores.

\section{Ingestive behavior of sheep in tropical grass}

\section{SUMMARY}

\section{ADDITIONAL KEYWORDS}

Animal behaviour.

Sheep production.

Grazing.

Brazil.

\section{INFORMATION}

\section{Cronología del artíiculo.}

Recibido/Received: 01.04.2017

Aceptado/Accepted: 27.03 .2018

On-line: 15.04 .2018

Correspondencia a los autores/Contact e-mail:

sheillammoreira@gmail.com

\section{INTRODUÇÃO}

A ovinocultura se caracteriza por ser uma excelente fonte de renda para o produtor rural, principalmente, devido à diversidade de matérias-primas obtidas (carne, lã, leite e pele). Merece destaque a adaptabilidade e rusticidade da espécie ovina aos mais distintos ambientes, tendo como base a alimentação pastoril (Barba et al. 2016, pp. 447-48; Vidal-Gonzáles et al. 2016, p.
435), bem como a possibilidade de gerar produtos com características únicas, providas do ambiente de origem, que permitem agregar valor à cadeia produtiva (VidalGonzáles et al. 2016, p. 434). Santos et al. (2008, p. 1), comenta que a criação de ovinos se apresenta com crescimento geométrico no Brasil, fruto do alto valor pago à carne de cordeiro, ciclo rápido de produção e idade ao abate reduzida (90 e 120 dias), com peso vivo entre 30 e $35 \mathrm{~kg}$. 
A diversidade de produtos obtidos através da exploração ovina gera a necessidade de maiores informações sobre o comportamento ingestivo desta espécie, visto que, a compreensão deste comportamento pode nortear a adequação de manejo, visando assim aumentar a produtividade e o bem-estar dos animais.

Os princípios mais estudados para a caracterização do comportamento ingestivo dos ruminantes são: tempo, períodos e eficiência de alimentação ou ruminação e número de alimentações (Macedo et al. 2007, p. 1911). O entendimento do comportamento de pastejo, do horário das várias atividades, da relação dos animais com a qualidade e quantidade de forragem e com outros fatores do meio, contribui para melhorar o bem-estar (Gonyou 1994, p. 2174) e, por consequência, o desempenho dos animais (Fraser 2000, p. 11).

Diferentes alimentos, passíveis de utilização na alimentação dos ruminantes, podem causar alterações no comportamento ingestivo dos animais, interferindo nas atividades de alimentação, ruminação e ócio. Após, quando estas informações são interpretadas, juntamente com outros fatores, nos dão condições de avaliar se o alimento fornecido se encontra adequado do ponto de vista nutricional (Carvalho et al. 2014, p. 55).

De maneira geral, os fatores que afetam o comportamento ingestivo estão ligados ao alimento, ao ambiente e ao animal, sendo que, esta interação pode ser medida através de três parâmetros: tamanho de bocado, tempo de pastejo e taxa de bocado (Brâncio et al. 2003, p. 1047). Hodgson (1982) e Provenza \& Lauchbaungh (1990) comentam que animais em pastejo possuem uma imensa habilidade de modificar o seu comportamento para responder às mudanças no ambiente.

Dentre os herbívoros, os ovinos caracterizam-se pela capacidade de adaptação às mais diversas condições de ambiente. Isso deve-se aos animais desta espécie adaptarem-se bem às diferentes dietas, associada à sua acentuada capacidade de aclimatação (Cunha et al. 1997, p. 106)

No Brasil, as principais pastagens utilizadas para ruminantes são as gramíneas tropicais, devido ao seu rápido crescimento em condições favoráveis de temperatura e umidade no solo, concentrando mais de $70 \%$ da produção de matéria seca durante a primavera/ verão (Santos 2002, p. 62; Pandolfi Filho et al. 2016, p. 214). A espécie forrageira influencia diretamente na resposta do animal, principalmente, quando submetido à diferentes ofertas de forragem, diferenças de qualidade nutricional entre as espécies forrageiras e à facilidade de colheita das mesmas, relacionadas a diferenças estruturais no relvado (Poppi et al. 1987, p. 61).

A estrutura do pasto é uma característica primordial e determinante, tanto na competição entre as comunidades vegetais, quanto no comportamento ingestivo dos animais em pastejo (Carvalho et al. 2001, p. 853; Laca \& Lemaire, 2002). A quantidade de alimento consumida em determinado período de tempo é afetada pelo o número de refeições, duração e a velocidade de ingestão de forragem, sendo que, os diferentes estádios fenológicos das forrageiras podem influenciar o peso e/ou frequência do bocado ou o tempo de pastejo, afetando também o período de ruminação (De Paula et al. 2009, p. 43).

Em vista disto, o objetivo desta revisão foi discorrer sobre os principais fatores que interferem no comportamento ingestivo de ovinos manejados em gramíneas tropicais.

\section{GRAMÍNEAS TROPICAIS}

Pastagens tropicais apresentam lâminas foliares longas, fazendo com que os animais adotem uma estratégia de pastejo tipo "espaguete" para sua captura (Carvalho et al. 2001, p.865).

Conforme afirmam Sollenberger \& Burns (2001), a forma que as laminas foliares são oferecidas aos animais e o grau com que estas são apreendidas em separado do colmo e do material morto de baixa digestibilidade são relevantes em pastagens baseadas em espécies C4.

Hodgson \& Silva (2002), comentam que gramíneas do gênero Brachiaria, são responsáveis por cerca de $80 \%$ de toda a área de pastagens cultivadas no Brasil. Dentre as espécies, a Brachiaria brizantha se destaca frente as demais (Pandolfi Filho et al. 2006, p. 214) e, com isso, tem aumentado sua participação nas áreas ocupadas, substituindo, principalmente, B. decumbens. Isso se deve, em grande parte, a sua resistência ao ataque da cigarrinha-das-pastagens (Zimmer \& Euclides Filho, 1997) e também à maior produtividade. Pedreira et al. (2007, p. 283), declaram que a Brachiaria decumbens, quando manejada em alturas inferiores a $10 \mathrm{~cm}$, apresenta menor massa de forragem e reduzida massa de lâminas foliares, o que limita a fotossíntese e o crescimento do dossel. No entanto, relvados de Brachiaria brizantha com altura superior a $40 \mathrm{~cm}$, apresentam maiores taxas de senescência e alongamento de colmos, o que diminui a relação folha/colmo, bem como o incremento da massa de tecidos mortos, caracterizando uma estrutura desfavorável ao consumo e desempenho animal (Carvalho et al. 2001, p. 866), em virtude disso, para otimizar a produção do capim Marandú, atualmente recomenda-se que os pastos sejam mantidos com altura entre $20 \mathrm{~cm}$ e $40 \mathrm{~cm}$ (Sbrissia 2004, p.117).

O milheto (Pennisetum americanum) é bastante utilizado nos sistemas de produção animal do Sul do Brasil. Esta gramínea apresenta capacidade de se adaptar a uma grande variedade de solos, não tolera os encharcados, e se conduz bem em baixa fertilidade e alta acidez, onde é difícil de cultivar o sorgo e o milho (Belli 2011, p. 15).

Belli (2011, p. 15), comenta que os animais devem ser colocados na pastagem de milheto quando as plantas atingirem de 40 a $50 \mathrm{~cm}$ de altura e a carga animal deve ser ajustada afim de manter a altura do dossel entre 20 e $30 \mathrm{~cm}$. O controle adequado da oferta de forragem é importante fator para uma boa exploração desta forrageira, visto que erros de manejo comprometem a estrutura do pasto (Moraes \& Maraschin 1988, p. 201).

O sorgo consiste em planta típica de clima quente, Cabral Filho (2004, p. 1) ressalta que, devido sua alta capacidade de produção, é muito empregado na ali- 
mentação animal. O autor ainda relata a importância da fonte energética dos grãos de sorgo em dietas de monogástricos e ruminantes, podendo ser uma ótima opção em substituição a cereais como o milho e o trigo.

O sorgo, assim como outras gramíneas de metabolismo C4, caracteriza-se por apresentar altas taxas fotossintéticas e rápida elongação de colmos. Assim, Puntel (2010, p.17), comenta que o sorgo é amplamente utilizado para a confecção de silagem, sendo dificultado seu uso em pastejo pelo difícil manejo, em virtude do acelerado crescimento.

Em virtude das limitações apresentadas pelas cultivares de sorgo, geralmente as variedades destinadas ao pastejo são obtidas através de cruzamentos com capim sudão (Sorghum sudanense (Piper) Stapf) ou genótipos selecionados para alta rusticidade e grande capacidade de rebrote, após cortes ou pastejos sucessivos (Leite 2006, p. 15). Entretanto, informações sobre o manejo de alturas de pastejo são escassas na literatura, visto o grande risco de intoxicação por precursores do ácido cianídrico (Juffo et al. 2012, p. 218) em plantas com alturas menores que $50 \mathrm{~cm}$.

Mattos (2003, p. 61) salienta que o capim sudão (Sorghum sudanense) tem alta capacidade de se recuperar após corte ou pastejo a alturas mais baixas, sendo melhor do que a maioria das gramíneas anuais, proporcionando altos rendimentos e qualidade de forragem. Todavia, assim como o sorgo, apresenta relatos sobre a presença de glicosídeos cianogênicos que, em determinadas situações, causa morte de animais após o consumo. Cabe ressaltar que as informações existentes na literatura, quanto a toxidade das cultivares de capim sudão são escassas e muitas vezes divergentes.

Dentre os precursores do HCN no gênero Sorghum está a durrina, glicosídeo cianogênico que age como composto de defesa, liberando cianeto após a clivagem por uma $\beta$ - glicosidase (Wink, 2001, p. 444), geralmente quando a planta (célula) é rompida ou cortada no momento da ingestão. No caso dos ruminantes, a liberação de cianeto ocorre no rúmen, durante a ruminação. A concentração de durrina na planta varia com adubação nitrogenada, diminuição do crescimento causado por variações climáticas ou doenças, mas principalmente com o estágio de desenvolvimento da planta, sendo que, novos rebrotes apresentam altas quantidades de glicosídeos cianogênicos comparados com plantas mais velhas (Busk \& Moller 2002, p. 1226).

O Panicum maximum cv. Aruana é, dentre os panicums, o que apresenta menor porte, com cerca de 50 $\mathrm{cm}$ de altura, podendo ser implantado por sementes. Barbosa et al., (2003, p.56) comenta que o capim Aruana apresenta elevada produção por área, bom valor nutritivo e elevada aceitabilidade pelos animais, sem apresentar princípios tóxicos ou antinutricionais, estando bastante disseminada no Sudeste do Brasil, em solos de maior fertilidade.

O capim Aruana se enquadra na faixa dos capins mais exigentes. As características morfogênicas e estruturais dessa cultivar sofrem tanto a influência da frequência e intensidade do pastejo adotado, quanto das condições edafoclimáticas, o que implica na capa- cidade e velocidade do restabelecimento para o pastejo, sendo de porte menor e perfilhamento mais intenso que os demais cultivares, mostra boa adaptação aos hábitos de pastejo da espécie ovina (Santos et al. 2002; Zanini et al. 2012, p.1850).

\section{FATORES INTRÍNSECOS AO BOCADO}

A menor escala de decisão do animal é o bocado, que significa a ação ou o ato de apreender a forragem com os dentes (Gibb, 1996), sendo baseado nos fatores relacionados a esta ação, tais como: taxa, peso, volume e profundidade de bocado, que é capaz de estimar a ingesta de alimentos efetuada pelo animal.

Santos et al. (2010, p. 6) descrevem os lábios e os pequenos dentes incisivos como as principais estruturas de apreensão de alimentos dos ovinos e, diferentemente dos bovinos, a língua não é utilizada para este fim. Assim, os ovinos são mais eficientes no processo de apreensão e separação do alimento, possibilitando maior seletividade da forragem, assim, optando, sempre que possível, pelas partes mais tenras e palatáveis da planta (Carvalho et al. 2001, p. 858).

Delagarde et al. (2001, p. 167) relatam que, em condições onde há baixa disponibilidade de massa de forragem, os ovinos realizam até 65 bocados por minuto, entretanto, quando a oferta existente é satisfatória, a frequência de bocados pode cair pela metade. Em outras palavras, à medida que diminui a massa de forragem na pastagem, a massa de cada bocado também diminui, refletindo a condição de baixa disponibilidade de biomassa ávida ao consumo (Carvalho et al. 2001, p.858), fazendo com que os animais aumentem os períodos em pastejo, refletindo em altas taxas de bocados.

Todavia, Carvalho et al. (2001, p. 860) reiteram que o consumo diminui na medida em que o decréscimo da massa de cada bocado não consegue ser "compensada" pelo aumento na frequência dos mesmos. Penning et al. (1994, pp. 480-82), em experimento investigando os efeitos da troca de sistema de criação, de pastejo contínuo para rotacionado, sobre a ingestão e comportamento de ovelhas, observaram que a altura da forragem não interfere no número de movimentos mandibulares executados pelos animais. No entanto, a distinção dos diferentes movimentos mandibulares, entre movimentos de apreensão e de mastigação, possibilitou constatar que a redução na disponibilidade de forragem acarreta no aumento do número de movimentos de apreensão e na diminuição do número de mastigações, mantendo estável o número total de movimentos.

Outro fator envolvido no comportamento ingestivo á a profundidade do bocado, que pode responder de maneira linear e positiva ao aumento na altura do pasto (Silva, 2006). Burlinson et al. (1991, p. 33), afirmam que a profundidade de bocado pode ser limitada por diversos fatores, tais como: a força empregada para cortar a forragem em estrato mais profundo, o comprimento de folha ou colmo no qual o animal se sente confortável para manipular e a presença de material 
morto ou infecção fúngica nos níveis inferiores do perfil do pasto.

Burlinson et al. (1991, p. 36), ao trabalhar com ovinos, constataram que área de bocado foi afetada diretamente pela altura da pastagem. Todavia, a área de bocado é menos sensível do que a profundidade do bocado em resposta às características da pastagem (Hodgson et al., 1997).

Pedroso et al. (2004, p. 1343), afirmam que quando ocorre maior proporção de folhas na pastagem há incremento na taxa e peso de bocados. Entretanto, quando a forragem não apresenta elevada quantidade de folhas, as ovelhas reduzem o peso de bocados, aumentam o intervalo entre estes e o tempo total de pastejo, sinalizando a preferência dos animais por material de melhor qualidade.

\section{PERÍODO E DURAÇÃO DE PASTEJO}

O tempo de pastejo é outro fator primordial na obtenção de alimentos para ruminantes, visto que os herbívoros têm o desafio de se alimentarem de um recurso que é complexo e dinâmico no tempo e no espaço (Laca 2008, p.83), ou seja, a pastagem tem sua composição físico-quimica e estrutural modificada ao longo do tempo. Simultaneamente, os animais têm seu estado interno modificado, pois sua condição corporal, seus requerimentos e seu nível de aprendizado em relação ao ambiente alimentar, dentre outros, evoluem ao longo do tempo (Laca 2008, p. 86).

Os ruminantes gastam seu tempo em atividades de pastejo, ruminação, interações sociais e ócio, todavia, o tempo despendido em cada atividade realizada pelo animal, depende de fatores como: características do pasto, condições ambientais e das exigências nutricionais do animal (Hodgson, 1982; Macoon, 1999).

Em pasto livre, os ovinos pastejam basicamente no período diurno, apresentando dois 'picos de pastejo' ao amanhecer e ao final da tarde, sendo finalizado próximo ao pôr-do-sol. Os animais consomem, em média, entre $2 \%$ e $5 \%$ de seu peso corporal por dia de pastagem, e o tempo de pastejo varia de acordo com a disponibilidade e o tipo de alimento (Ortêncio Filho et al., 2008, p. 981).

Jensen (2002, p.14), relata que a preferência dos animais em pastejar durante o período diurno é provavelmente uma resposta adaptativa afim de evitar possíveis predadores. Medeiros et al. (2007, p. 201) observaram maior competição por consumo de forragem em períodos próximos ao amanhecer e ao final da tarde, fato que pode ser explicado, provavelmente, pelas temperaturas mais amenas nesses períodos.

Os ovinos geralmente distribuem a ingesta de alimentos durante o dia em 3 a 5 períodos, sendo que, dificilmente ultrapassam 12 horas em pastejo (Poppi et al. 1987; Carvalho et al. 2001, p. 864; Silva, 2006), uma vez que, tempos de pastejo acima de 720 minutos podem interferir nas atividades de ruminação e comportamentais do animal em questão.

A disponibilidade forrageira influencia no tempo total de pastejo, onde, quanto menor a oferta, menor é o tempo total de pastejo, ou seja, o animal realiza maior número de refeições curtas, realizadas de forma intercalada, com intervalos mais longos entre refeições (De Paula et al. 2009, p. 46). Ainda, Cunha et al. (1997, p. 106), ressaltam que as condições ambientais também interferem no comportamento de pastejo dos ovinos, apontando a importância de considerar estes fatores no estabelecimento do manejo, bem como prever condições de sombreamento como um fator decisório durante o período da implantação das pastagens.

\section{PREFERÊNCIA ALIMENTAR E HÁBITOS DE PASTEJO}

Os ovinos possuem comportamento de pastejo gregário (em lotes), este hábito pode ser explicado pelo fato destes animais serem considerados presas, e no processo de evolução da espécie, este comportamento é discriminado como um mecanismo de proteção a possíveis ataques de predadores (De Paula et al. 2009, p. 47). Boissy \& Dumont (2002, p. 238) estudando interações sociais e alimentares sobre o comportamento de pastejo, constataram que, quando os herbívoros estão em grupos maiores, os animais exploram lugares mais distantes e, quando estão em grupos menores, pastam mais próximos dos lugares familiares. Penning et al. (1993, p. 106), verificaram que o tempo de pastejo diminui quando o grupo de animais é inferior a três.

Ao iniciarem o pastejo em um local, os ovinos realizam antecipadamente uma avaliação visual, estabelecendo referências em termos qualitativos e quantitativos da forragem disponível. Quando esta se encontra abaixo da média estabelecida, o animal se desloca em busca de um local que lhe garanta um melhor consumo de forragem (Palhano et al. 2002, p. 46).

A preferência em relação as características das forrageiras é modificada conforme os fatores abióticos modificam as características das comunidades de plantas (Santos et al. 2010, p. 16). Lâminas foliares são os componentes da planta preferencialmente consumidos, devido ao menor gasto de energia requerido para sua colheita em relação aos caules (Hendricksen \& Minson 1980, p. 550), e conforme descrito por Minson (1990), as laminas foliares também apresentam menor resistência à quebra pela mastigação e, consequentemente, permanecem menos tempo retidas no rúmen.

Silveira (2001, p. 109) avaliando o comportamento ingestivo de cordeiros, em diferentes alturas da pastagem de azevém (Lolium multiflorum Lam.), constatou que, quanto maior a altura do pasto, maior o intervalo entre as refeições e maior o tempo destinado para as outras atividades. Isso se justifica pelo fato destes componentes de menor qualidade demandarem maior tempo para serem digeridos e, deste modo, maior tempo de ruminação (De Paula et al. 2009, p.47). Corroborando, Monteiro et al. (2006, p. 1), determinam que a rejeição por alturas maiores de forragem ocorre devido à predileção dos animais pelo extrato inferior das plantas, onde se encontram folhas novas e brotos. Somado a isso, há o fato de que os ovinos são considerados presas, por isso é imprescindível que eles possam visualizar os demais membros do grupo, fato este que poderia ser dificultado em pastagens de alturas elevadas (De Paula et al. 2009, p. 47). 


\section{FATORES RELACIONADOS A RUMINAÇÃO E ÓCIO}

Os períodos gastos com a ingestão de alimentos são intercalados com um ou mais períodos de ruminação ou de ócio. O tempo gasto em ruminação é mais prolongado à noite, mas os períodos de ruminação são ritmados também pelo fornecimento de alimento (Zanine et al. 2006, p. 116). Fraser \& Broom (1990), destacam a ruminação, como a atividade que demanda mais tempo depois do pastejo, sendo dividida em 15 a 20 vezes ao longo do ciclo diário, podendo haver uma variação de poucos minutos a mais de uma hora.

Os períodos de ruminação e ócio ocorrem entre as refeições, existindo diferenças entre indivíduos quanto à duração e repetição dessas atividades, que parecem estar relacionadas às condições climáticas e de manejo, ao apetite dos animais, à exigência nutricional e, principalmente, à relação volumoso:concentrado da dieta (Silva et al., 2009). Van Soest (1994), afirma que o tempo despendido em ruminação sofre influência da natureza da dieta e é, certamente, proporcional ao teor de parede celular dos volumosos, assim, quanto mais elevado o teor de fibra na dieta, maior será o tempo aplicado em ruminação.

A forma física da dieta influencia o tempo despendido nos processos de mastigação e ruminação (Dado \& Allen 1995, p. 139). Alimentos concentrados e fenos finamente triturados ou peletizados reduzem o tempo de ruminação, enquanto volumosos com alto teor de parede celular tendem a elevar o tempo com essa atividade. $\mathrm{O}$ aumento do consumo tende a reduzir o tempo de ruminação por grama e alimento, fator provavelmente responsável pelo aumento do tamanho das partículas fecais, quando os consumos são elevados (Van Soest, 1994).

Cardoso et. al. (2006, p. 607), avaliando o comportamento ingestivo de cordeiros alimentados com dietas contendo diferentes níveis de fibra em detergente neutro, encontraram valores médios para os tempos de alimentação (205,25 min/dia) e de ruminação (487,25 min/dia). Entretanto, Turino (2003, p. 41), trabalhando com dietas que continham alta proporção de concentrado e 18\% de FDN na MS, encontrou médias de 154,8 e 215,4 min/dia para alimentação e ruminação, respectivamente.

Schwarz \& Malaquias (2012, pp. 832-33), encontraram tempo médio, em minutos, do comportamento das fêmeas em pastejo $(114,37$ min166,39), ruminação $(17,92$ min20,73) e ócio $(20,21$ min26,46) e dos machos em pastejo $(111,67 \min 168,28)$, ruminação $(18,75 \min 18,49)$ e ócio $(22,08 \mathrm{~min} 27,82)$. Conquanto, os mesmos autores, tenham observado que o tempo de pastejo médio das fêmeas $(114,37 \mathrm{~min}$.) foi maior comparado ao dos machos $(111,67$ min.), não foi observado interação com significância estatística entre a situação (pastejo, ruminação e ócio) e o sexo do animal.

\section{COMPORTAMENTO INGESTIVO DE OVINOS EM GRAMÍ- NEAS TROPICAIS}

Sempre que se abordam as relações entre a estrutura da pastagem e o processo de pastejo dos animais, questiona-se sobre a existência de informações em pastagens tropicais serem raras (Carvalho et al. 2001, p. 862). A altura, a densidade, as diferentes partes da planta, a composição botânica do dossel e o arranjo espacial, são fatores que afetam a ingestão e digestão de plantas forrageiras, afetando diretamente o comportamento ingestivo de animais herbívoros (Sollenberger \& Burns, 2001).

Stobbs (1973, p. 828), relata que, em pastagens tropicais, a densidade volumétrica e a relação folha/colmo teriam maior relevância na determinação do comportamento ingestivo dos animais do que quando comparado a pastagens temperadas. Hodgson (1983, p.38), afirma que a influência da densidade de forragem sobre a massa do bocado, em pastagens tropicais, ainda não permite chegar a conclusões mais generalizadas, em virtude da heterogeneidade da estrutura das plantas estudadas.

Carvalho et al. (2001, p. 863) ressaltam que, se considerarmos o bocado como unidade básica de aquisição de nutrientes, pode-se descrever o processo de pastejo em três etapas, não necessariamente excludentes. Estas etapas são classificadas em: tempo de procura pelo bocado (etapa 1), tempo para ação do bocado (etapa 2) e tempo de manipulação do bocado (etapa 3).

A etapa 2, comentada por Carvalho et al (2001, p. 865), é composta por uma série de movimentos que visam, essencialmente, ampliar a área do bocado. $\mathrm{O}$ mesmo autor investiga a hipótese que, estritamente em pastagens tropicais, esta etapa poderia ser limitante no consumo dos animais, principalmente quando há alta oferta de forragem e/ou com alto acúmulo de material senescente no perfil da pastagem. Nesta conjuntura, a dispersão espacial das folhas poderia limitar a ingestão de forragem não por falta de densidade, e sim, por um aumento no tempo necessário ao processo de captura da folha até a boca do animal.

Castro (2002, p. 89), utilizando ovinos em pastejo com diferentes alturas da pastagem de milheto (10, 20, 30 e 40 $\mathrm{cm})$, verificou produção de forragem de 10,3 t/ ha de MS conduzindo a pastagem com altura de $10 \mathrm{~cm}$; enquanto que, ao manejar a mesma pastagem com alturas próximas de $30 \mathrm{~cm}$, esta produção praticamente dobrou, passando a ser de $18,8 \mathrm{t} /$ ha de MS.

\section{CONSIDERAÇÕES FINAIS}

A ovinocultura representa grande importância para o setor produtivo mundial, em virtude disso, constata-se que há necessidade de conhecer os hábitos destes animais, afim de que se possa realizar um manejo mais adequado as necessidades desta espécie.

Pode-se identificar ambientes pastoris adequados por meio do comportamento ingestivo dos animais. A informação sobre o comportamento de pastejo de ovinos é influenciada por diversos fatores, dentre eles podemos citar: o clima, o horário de pastejo, a característica, estrutura e oferta forrageira. Em termos práticos, ao proporcionarse uma boa interação planta-animal, respeitando também os horários de pastejo, pode-se obter melhores índices de bem-estar dos animais e, consequentemente, melhores índices produtivos.

Os dados sobre o comportamento ingestivo de ovinos em gramíneas tropicais ainda são deficientes e, em virtude da heterogeneidade desta categoria de plantas, há grande divergência entre os autores. Neste contexto, faz-se necessário maiores estudos sobre o tema. 


\section{BIBLIOGRAFIA}

Barba, C, Fernández-Tomillo, L, Jiménez, R, Guzmán, JR \& García, A 2016, 'Valor ecológico ambiental y conservación de razas ovinas en peligro de extinción en Andalucía', Archivos de Zootecnia, vol. 65, no. 251, pp. 445-48.

Barbosa, C, Bueno, M, Cunha, E, Santos, L, Estrada, L, Quirino, C \& Silva, J 2003, 'Consumo voluntário e ganho de peso de borregas das raças Santa Inês, Suffolk e lle de France, em pastejo rotacionado sobre Panicum maximum jacq. cvs Aruana ou Tanzânia', Boletim de Indústria Animal, vol. 60, no. 1, pp. 56-66.

Belli, C 2011, 'Comportamento ingestivo de vacas Jersey em pastagens tropicais anuais', Trabalho Conclusão de Curso (Graduação) - Universidade Tecnológica Federal do Paraná, Dois Vizinhos.

Boissy, A \& Dumont, B 2002, 'Interactions between social and feeding motivations on the grazing behaviour of herbivores: sheep more easily split into subgroups with familiar peers', Applied Animal Behaviour Science, vol. 79, no 3, pp. 233-45.

Brâncio, P, Euclides, V, Nascimento Junior, D, Fonseca, D, Almeida, R, Macedo, M \& Barbosa, R 2003, 'Avaliação de três cultivares de Panicum maximum Jacq. sob pastejo: comportamento ingestivo de bovinos', Revista Brasileira de Zootecnia, vol. 32, no. 5, pp. 1045-46.

Burlinson, A, Hodgson, J \& Illius, A 1991, 'Sward canopy structure and the bite dimensions and bite weight of grazing sheep', Grass and Forage Science, vol.46, no.1, pp.29-38.

Busk, P \& Møller, B 2002, 'Dhurrin synthesis in sorghum is regulated at the transcriptional level and induced by nitrogen fertilization in older plants', Plant Physiology, vol. 129, no. 3, pp. 1222-31.

Cabral Filho, S 2004, 'Efeito do teor de tanino do sorgo sobre a fermentação ruminal e parâmetros nutricionais de ovinos', Tese de Doutorado, Universidade de São Paulo.

Cardoso, D, Carvalho, S, Galvani, B \& Pires, C 2006, 'Comportamento ingestivo de cordeiros alimentados com dietas contendo diferentes níveis de fibra em detergente neutro', Ciência Rural, vol. 36, n. 2, pp. 604-09.

Carvalho, PCF, Ribeiro Filho, HMN, Poli, CHEC, Moraes, A \& Delagarde, R 2001, 'Importância da estrutura da pastagem na ingestão e seleção de dietas pelo animal em pastejo', In: Reunião Anual da Sociedade Brasileira de Zootecnia, Piracicaba: Fealq, pp. 853-871.

Carvalho, S, Dias, F, Pires, C, Brutti, D, Lopes, J, Santos, D, Barcelos, R, Macari, S, Wommer, T \& Griebler, L 2014, 'Comportamento ingestivo de cordeiros Texel e Ideal alimentados com casca de soja', Archivos de Zootecnia, vol. 6, no.241, p.55-64.

Castro, C 2002, 'Relações planta-animal em pastagem de milheto (Pennisteum americanum (L.) Leeke.) Manejada em diferentes alturas com ovinos', Dissertação de Mestrado, Universidade Federal do Rio Grande do Sul, Porto Alegre.

Cunha, E, Santos, L, Roda, D, Possi, C, Otsuk, I, Bueno, M \& Rodrigues, C 1997, 'Efeito do sistema de manejo sobre o comportamento em pastejo, desempenho ponderal e infestação parasitária em ovinos suffolk', Pesquisa Veterinária Brasileira, vol. 17, no 3-4, pp. 1005-1011.

Dado, R \& Allen, M 1994, 'Variation in and relationships among feeding, chewing, and drinking variables for lactating dairy cows', Journal of Dairy Science, vol. 77, no. 1, pp. 132- 144.

Delagarde, R, Prache, S, D'Hour, P \& Petit, M 2001, 'Ingestion de l'herbe par les ruminants au pasturage', Fourrages, vol. 166, pp. 189-212.

De Paula, E, Stupak, E, Zanatta, C, Poncheki, J, Leal, P \& Monteiro, A 2009, 'Comportamento ingestivo de ovinos em pastagens: Uma revisão, Revista Trópica-Ciências Agrarias e Biologicas, vol. 4, no. $1, \mathrm{pp} .42-51$.

Fraser, A 2000, Farm Animal Behaviour, 1rd edn, The Macmillan Publishing Company, New York, USA.

Fraser, A \& Broom, D 1990, Farm animal behaviour and welfare, 3rd edn, London, Bailliere Tindall.

Gibb, M 1996, 'Animal grazing/intake terminology and definitions', In: Pasture ecology and animal intake,proceedings, 3rd end, Dublin, pp.21-37.
Gonyou, H 1994, 'Why the study of animal behavior is associated with the animal welfare issue,' Journal of Animal Science, vol. 72, no. 8, pp. 2171-77.

Hendricksen, R \& Minson, D 1980, 'The feed intake and grazing behaviour of cattle grazing a crop of Lablab Purpureus cv. Rongai,' Journal Agricultural Science, vol. 95, no. 3, pp. 547-57.

Hodgson, J 1982, 'Ingestive behavior', In: Leaver, JD (ed.) Herbage intake handbook, London, British Grassland Society, pp. 113-38.

Hodgson, J 1983, 'A relación entre laestructura de laspraderas y lautilización de las plantas forrajerastropicales', In: Paladines, $\mathrm{O}$, Lascano, C, Germoplasma forrajero bajo pastoreo em pequenas parcelas, Cali, CIAT, pp. 33-48.

Hodgson, J, Coosgrove, G \& Woodward, S 1997, 'Research on foraging behaviour: progress and priorities', In: International grassland congress, Winnipeg, Canada, 18rd end, pp.109-18.

Hodgson, J \& Silva, S 2002, 'Options in tropical pasture management,' In: Reunião Anual da Sociedade Brasileira de Zootecnia, Recife, pp. 180-202.

Jensen, P 2002, 'The Ethology of Domestic Animals - An Introductory Text,' Oxon, CABI Publishing.

Juffo, G, Pavarini, S, Wouters, F, Oliveira, L, Antoniassi, N, Cruz, C \& Driemeier, D 2012, 'Intoxicação espontânea por Sorghum Sudanense em bovinos leiteiros no Rio Grande do Sul, Pesquisa Veterinária Brasileira, vol. 32, no. 3, pp. 217-20.

Laca, E, 2008, 'Foraging in a heterogeneous environment: intake and diet selection'. In: Prins, H \& Vann Langeveld, F (Eds.) Resource Ecology: Spatial and Temporal Dynamics of Foraging, Wageningen UR Frontis Series, pp.81-00.

Laca, E \& Lemaire, G 2000, 'Medição da estrutura do pasto', In: Mannetje, L \& Jones, R (Eds.) Métodos laboratoriais para a pesquisa pastagens e produção animal, Wallingford, CABI Publication, pp. 103-21.

Leite, D 2006, 'Farelo de glúten de milho e farelo de arroz desengordurado na suplementação de bovinos de corte, Dissertação de Mestrado, Programa de Pós-Graduação em Zootecnia, Centro de Ciências Rurais, Universidade Federal de Santa Maria, Santa Maria.

Macedo, CAB, Mizubuti, IY, Moreira, FB, Pereira, ES, Ribeiro, ELA, Rocha, MA, Ramos, BMO, Mori, RM, Pinto, AP, Alves, TC \& Casimiro, TR 2007, 'Comportamento ingestivo de ovinos recebendo dietas com diferentes níveis de bagaço de laranja em substituição à silagem de sorgo na ração', Revista Brasileira de Zootecnia, vol. 36, no. 6, pp. 1910-16.

Macoon, B 1999, 'Forage and Animal Responses in Pasture-Based Dairy Production Systems for Lactating Cows', Ph.D. dissertation, University of Florida.

Mattos, J 2003, 'Gramíneas forrageiras anuais alternativas para a região do Brasil central', Revista do Programa de Ciências Agro-Ambientais, vol. 2, no. 1, pp. 52-70.

Medeiros, R, Pedroso, C, Jornada, J, Silva, M \& Saibro, J 2007, 'Comportamento ingestivo de ovinos no período diurno em pastagem de azevém anual em diferentes estádios fenológicos', Revista Brasileira de Zootecnia, vol. 36, no. 1, pp. 198-04.

Minson, D 1990, Forage in ruminant nutrition. 1rd end, San Diego: Academic Press.

Monteiro, ALG, Poli, CHEC, Moraes, A 2006, Pastagens para ovinos, Farmpoint Ovinos e Caprinos, 30 Maio, Acesso 17 Março 2018, <http://www.farmpoint.com.br/?noticialD=22\&actA=7\&arealD=3 \&secaolD $=29>$.

Moraes, A \& Maraschin, G 1988, 'Pressões de pastejo e produção animal em milheto cv. Comum'. Pesquisa Agropecuária Brasileira, vol. 23, no. 2, pp. 197-05

Ortêncio Filho, H, Barbosa, O, Sakaguti, E, Onorato, W \& de Macedo, F 2008, 'Efeito da sombra natural e da tosquia no comportamento de ovelhas das raças Texel e Hampshire Down, ao longo do período diurno, no Noroeste do Estado do Paraná', Acta Scientiarum, vol. 23, no. 4, pp. 981-93.

Palhano, A, Carvalho, P \& Barreto, M 2002, 'Influência da estrutura da pastagem na geometria do bocado e nos processos de procura 
e manipulação da forragem', Tuiuti: Ciência e Cultura, vol. 2, no. 31, pp. 33-52.

Pandolfi Filho, $A D$, Do Valle, CB, Barrios, SCL, Alves, GF \& Deminicis, BB 2016, 'Avaliação de genitoras sexuais de Brachiaria spp. na época seca', Archivos de. Zootecnia, vol. 65, no. 250, pp. 213-19.

Pedreira, B, Pedreira, C \& Silva, S 2007, 'Estrutura do dossel e acúmulo de forragem de Brachiaria brizantha cultivar Xaraés em resposta a estratégias de pastejo', Pesquisa Agropecuária Brasileira, vol. 42, no. 2, pp. 281-87.

Pedroso, C, Medeiros, R, Silva, MA, Jornada, J, Saibro, J \&Teixeira, J 2004, 'Comportamento de ovinos em gestação e lactação sob pastejo em diferentes estádios fenológicos de azevém anual'. Revista Brasileira de Zootecnia, vol. 33, no. 5, pp. 1340-44.

Penning, P, Parsons, A, Newman, J, Orr, R \& Harvey, A 1993, 'The effects of group size on grazing time in sheep', Applied Animal Behaviour Science, vol. 37, no. 2, pp. 101-09.

Penning, PD, Parsons, AJ, Newman, JA, Orr, RJ \& Harvey, A 1994, 'Intake and behaviour responses by sheep to changes in sward characteristics under rotational grazing', Grass and Forage Science, vol. 49, no. 4, pp. 476-486.

Poppi, D, Hughes, T \& L'Huillier, P 1987, 'Intake of pasture by grazing ruminants', In: Nicol, A (Ed.). Livestock feeding on pasture, Halminton: New Zealand Society of Animal Production, pp. 55-64.

Provenza, F \& Lauchbaungh, K 1999, 'Foraging on the edge of chaos'. In: Lauchbaungh, K, Mosley, J \& Sanders, K (Eds.). Grazing behavior of livestock and wildlife, Moscow: University of Idaho, pp. 1-12.

Puntel, M, 2010, 'Dinâmica da pastagem de sorgo em diferentes ofertas de lâminas foliares na terminação de vacas de descarte', Dissertação de Mestrado. Universidade Federal de Santa Maria, Santa Maria.

Santos, B, Voltolini, T \& Salla, L 2010, 'Comportamento de PastoreioBehavior of grazing', Revista Electrónica de Veterinaria, vol. 11, no. 4 pp. 1-33.

Santos, LE, Bueno, MS, Cunha, EA, Estrada, L, Quirino, C \& Da Silva, J 2002, 'Manejo de pastagens para a produção ovina', In. Simpósio mineiro de ovinocultura: "agronegócio - ovinocultura", 2rd end, Lavras, Lavras: UFLA, pp. 105-140.

Santos LE, Cunha, EA, Bueno, MS \& Veríssimo, CJ 2008, Alimentação de Ovinos: Atualidades na produção Ovina em Pastagens, Acesso 09 Setembro 2016. <http:// http://www.iz.sp.gov.br/ $\mathrm{pdfs} / 1178134057 . \mathrm{pdf}$.

Santos, P 2002, 'Controle do desenvolvimento das hastes no capim Tanzânia: um desafio', Tese de doutorado, Universidade de São Paulo.

Sbrissia, A 2004, 'Morfogênese, dinâmica do perfilhamento e do acúmulo de forragem em pastos de capim-marandu sob lotação contínua', Tese de Doutorado. Escola Superior de Agricultura Luiz de Queiroz, Piracicaba.

Schwarz, D \& Malaquias, J 2012, 'Observações comportamentais de ovinos em pastejo no bioma Cerrado do Distrito Federal', Semina: Ciências Agrárias, vol. 33, no. 2, pp. 829-34.

Silva, S 2006, 'Comportamento animal em pastejo', In: $23^{\circ}$ Simpósio sobre manejo da pastagem. Piracicaba. Anais... Piracicaba, pp. 5-7.
Silva, T, Busato, K, Aragão, A, Chizzotti, M, Pereira, L, Barbosa, L \& Lima Silva, S 2009, 'Comportamento ingestivo de ovinos alimentados com diferentes níveis de manga em substituição ao milho', In: Reunião Anual da Sociedade Brasileira de Zootecnia, Maringá.

Silveira, E 2001, 'Produção e comportamento ingestivo de cordeiros em pastagem de azevém anual (Lolium multiflorum Lam) manejado a diferentes alturas', Porto Alegre. Dissertação de Mestrado. Universidade Federal do Rio Grande do Sul.

Sollenberger, L \& Burns, J 2001, 'Canopy characteristics, ingestive behavior and herbage intake in cultivated tropical grasslands', In: International Grassland Congress, 19rd edn, Piracicaba, SP, Proceedings... Piracicaba: FEALQ, pp. 321-27.

Stobbs, T 1973, 'The effects of plant structure on the intake of tropical pastures. II. Differences in sward Structure, nutritive value and bite size of animals grazing Setaria anceps and Chlorisgayana at various stages of growth', Australian Journal of Agricultural Research, vol. 24 , no. 6, pp. 821-29.

Turino, V 2003, 'Substituição da fibra em detergente neutro (FDN) do bagaço da cana de açúcar in natura pela FDN da casca da soja, em dietas contendo alta proporção de concentrado para cordeiros confinados', Dissertação de Mestrado, Universidade de São Paulo.

Van Soest, P 1994, Nutritional ecology of the ruminant', 2rd end. London: Constock.

Vidal-González, C, Barba, C, Perea, J, Angón, E, Puntas, JA \& Rouco, A 2016, 'Caracterización preliminar del sistema mixto ovino Segureño', Archivos de Zootecnia, vol. 65, no. 251, pp. 433-35.

Wink, M 2001, 'Special nitrogen metabolism', In Plant Biochemistry, Dey, P \& Harborne, J (eds), San Diego: Academic Press, pp. 439-86.

Zanine, A, Santos, E, Ferreira, D \& Graña, A 2006, 'Comportamento ingestivo de ovinos e caprinos em pastagens de diferentes estruturas morfológicas', Revista Electrónica de Veterinaria, vol. 2, no. 04, pp. 111-13.

Zanini, G, Santos, G \& Sbrissia, A 2012, 'Frequencies and intensities of desfoliation in Aruana guineagrass swards: morphogenetic and structural characteristics', Revista Brasileira de Zootecnia, vol. 41, no. 8, pp. 1848-57.

Zimmer, A \& Euclides Filho, K 1997, 'As pastagens e a pecuária de corte brasileira'. In: Gomide, J (ed.). Simpósio internacional sobre produção animal em pastejo, 1rd edn. Viçosa, Anais... Viçosa: UFV-DZO, pp.349-79. 